\title{
Updated gestational age specific birth weight, crown-heel length, and head circumference of Chinese newborns
}

\author{
T F Fok, H K So, E Wong, P C Ng, A Chang, J Lau, C B Chow, W H Lee, and the Hong \\ Kong Neonatal Measurements Working Group
}

See end of article for authors' affiliations

\section{Correspondence to}

Dr Fok, Department of Paediatrics, Prince of Wales Hospital, Shatin Hong Kong; taifaifok@cuhk.edu.hk

Accepted 5 August 2002

\begin{abstract}
Objective: To construct gestation specific standards of birth weight, crown-heel length, and head circumference of Chinese infants.

Design: A prospective cross sectional population study.

Methods: The birth weight, crown-heel length, and head circumference were prospectively measured using standard equipment in newborns delivered at 24-42 weeks gestation in the maternity units of 10 public hospitals and two private hospitals in Hong Kong. The findings were used to construct gestation specific standards of these variables. The LMS method using maximum penalised likelihood was used to perform model fitting. The results were compared with those obtained from a cohort of infants born in the same locality between 1982 and 1986.

Results: From October 1998 to September 2000, a total of 10032 infants were measured, representing $9.6 \%$ of the total deliveries in Hong Kong during that period. An extra 307 infants with gestation $\leqslant 35$ weeks were recruited from October 2000 to June 2001 . Each of the three variables showed a normal distribution at each gestational week. Gestation specific reference standards for each variable were constructed for male and female infants separately. Comparison with the 1982-1986 cohort showed a significant secular trend to increased birth weight. The trend was small, but significant, for crown-heel length and head circumference.

Conclusion: These growth standards will provide useful references for the care of newborns of ethnic Chinese origin. These standards, especially that for birth weight, should be updated regularly.
\end{abstract}

B irth weight, head circumference, and body length of newborn infants are important clinical indicators widely used for evaluation of prenatal growth and identification of infants that require detailed assessment and close monitoring during the neonatal period. Infants whose birth weights are too low or too high have higher mortality and morbidity than those of appropriate weight for gestation and increased risk of complications such as peripartum asphyxia, birth trauma, congenital malformations, and hypoglycaemia. ${ }^{1-5}$ Body length is also of prognostic significance: an infant who is underweight but of normal body length has normal growth potential, but a small infant with small body length probably has impaired growth potential because of genetic factors or infectious or other teratogenic insults in early fetal life. ${ }^{67} \mathrm{~A}$ recent study has shown that body length is also a predictor of perinatal mortality, with long infants being at higher risk of perinatal death. ${ }^{8}{ }^{9}$ Infants born with excessively small or large heads may have malformation of the central nervous system secondary to genetic or chromosomal abnormalities or teratogenic insults that carry grave prognostic implications.

Hong Kong, a British colony until July 1997, is a special administrative region of The People's Republic of China. Situated on the southern coast of China, $95 \%$ of its 6.8 million population are ethnic Chinese, most of whom are descendants of migrants from the southern provinces of China. ${ }^{10}$ The reference standards for birth weight, crown-heel length, and head circumference used in the region were those provided by Lubchenco et $a l^{112}$ until 1987, when local reference charts became available. These local references were based on measurements obtained from 8445 ethnic Chinese newborns born in Hong Kong between November 1982 and January 1986. ${ }^{13}$ Over the past decade, the region has evolved from an industrial city to a commercial and financial centre. Associ- ated with this change has been a rapid improvement in the standard of living and health indices, including infant and neonatal mortality. At the same time, the population has experienced an increasing growth rate from $1.1 \%$ in 1991 to $2.41 \%$ in 1996 , and a falling birth rate from 11.7 per thousand in 1991 to 7.4 per thousand in 1999. Most of the population increase has been due to net inflow of people, mainly from Southern China, which accounted for $24.7-87.9 \%$ of the net population increase in the 1990s. ${ }^{14}$ Over this time, health workers caring for newborns have noticed a trend of increasing size at birth of the local infants. A pilot study that we performed on 1350 full term newborns delivered in the Prince of Wales Hospital from January 1996 to April 1997 showed that the infants had greater gestation specific mean birth weight, crown-heel length, and head circumference than 15 years previously. In the light of these observations, a working group was formed to carry out a prospective study in 12 maternity units in the territory to establish a set of updated references for local infants.

\section{SUBJECTS AND METHODS}

The study was approved by the ethics committee on clinical research of The Chinese University of Hong Kong, and the ethics committees of the participating hospitals. In Hong Kong, all births take place in the maternity units of 20 hospitals. During the study period, about $70 \%$ of the newborns were delivered in the 10 public hospitals; the remaining 30\% were born in the 10 private hospitals. To ensure that the sample selected truly represented the newborn population in Hong Kong, the babies were recruited from the maternity units of all 10 public hospitals and two randomly selected private hospitals. 
Table 1 Characteristics of the parents of the study infants

\begin{tabular}{lll} 
& Mother & Father \\
\hline Education & & \\
No formal education & $114(1.1)$ & $31(0.3)$ \\
Primary school & $1179(11.4)$ & $941(9.1)$ \\
Secondary school & $7930(76.7)$ & $7403(71.6)$ \\
University & $1106(10.7)$ & $1964(19)$ \\
Occupation & & \\
Unemployed (including housewife) & $6152(59.5)$ & $186(1.8)$ \\
Professional & $352(3.4)$ & $662(6.4)$ \\
Non-manual worker & $3256(31.5)$ & $3453(33.4)$ \\
Manual worker & $579(5.6)$ & $6038(58.4)$ \\
Smoking & & \\
Non-smoker & $9584(92.7)$ & $5945(57.5)$ \\
Smoker & $755(7.3)$ & $4394(42.5)$ \\
• Quitted during pregnancy & $538(5.2)$ & \\
Alcohol consumption & $217(2.1)$ & \\
Never & & \\
Social drinking & $10019(96.9)$ & $7434(71.9)$ \\
Regular & $248(2.4)$ & $2429(23.5)$ \\
\hline
\end{tabular}

Values in parentheses are percentages.

Table 2 Birth weight $(\mathrm{g})$, crown-heel length $(\mathrm{cm})$, and head circumference $(\mathrm{cm})$ for boys

\begin{tabular}{|c|c|c|c|c|c|c|c|}
\hline \multirow[b]{2}{*}{ Gestation (weeks) } & \multirow[b]{2}{*}{$\mathrm{n}$} & \multicolumn{2}{|c|}{ Birth weight (g) } & \multicolumn{2}{|c|}{ Crown-heel length $(\mathrm{cm})$} & \multicolumn{2}{|c|}{ Head circumference $(\mathrm{cm})$} \\
\hline & & Mean & SD & Mean & SD & Mean & SD \\
\hline 24 & 9 & 664 & 87 & 322 & 31 & 226 & 5 \\
\hline 25 & 16 & 775 & 87 & 345 & 18 & 237 & 8 \\
\hline 26 & 12 & 886 & 64 & 352 & 13 & 248 & 10 \\
\hline 27 & 19 & 1109 & 184 & 373 & 14 & 253 & 15 \\
\hline 28 & 27 & 1156 & 168 & 378 & 20 & 262 & 14 \\
\hline 29 & 26 & 1303 & 200 & 403 & 25 & 271 & 16 \\
\hline 30 & 51 & 1476 & 190 & 408 & 18 & 281 & 14 \\
\hline 31 & 41 & 1640 & 261 & 427 & 22 & 290 & 15 \\
\hline 32 & 36 & 1896 & 399 & 434 & 28 & 300 & 20 \\
\hline 33 & 89 & 2057 & 374 & 447 & 27 & 307 & 16 \\
\hline 34 & 101 & 2234 & 354 & 455 & 21 & 312 & 13 \\
\hline 35 & 148 & 2514 & 415 & 472 & 21 & 321 & 15 \\
\hline 36 & 275 & 2803 & 419 & 482 & 20 & 331 & 14 \\
\hline 37 & 432 & 3053 & 413 & 493 & 19 & 336 & 11 \\
\hline 38 & 1054 & 3204 & 402 & 500 & 17 & 341 & 12 \\
\hline 39 & 1304 & 3291 & 383 & 505 & 17 & 343 & 11 \\
\hline 40 & 1179 & 3415 & 400 & 511 & 17 & 347 & 12 \\
\hline 41 & 544 & 3518 & 429 & 514 & 17 & 350 & 12 \\
\hline 42 & 115 & 3520 & 416 & 516 & 18 & 349 & 12 \\
\hline
\end{tabular}

All measurements were carried out by two teams of field workers, each consisting of two investigators who had received training in the use of all measuring equipment. The precision of their measurements was assessed by establishing the interobserver agreement of the measurements obtained from the first 100 infants. In random sequence, the teams were stationed in each of the participating public hospitals for two months, and attempts were made to capture all eligible infants born during that period. Thus the study would capture about one sixth of the annual deliveries in each of the hospitals. The antenatal history and condition of each infant were carefully evaluated. A data sheet was used to document parental data, as well as the medical and pregnancy history of the mothers. To obtain a reasonable sample of infants born in the private hospitals, measurements in the two participating private hospitals took place over one year. Logistically it was not possible to include more private hospitals, in which the newborn infants were under the care of a large number of private obstetricians and paediatricians.

The main study lasted for two years from October 1998 to September 2000. At the end of two years, it was realised that the number of infants $<35$ weeks gestation was relatively small. The study was then extended for nine months until June 2001 to enroll more preterm infants.

\section{Inclusion and exclusion criteria}

Singleton newborns of ethnic Chinese origin of gestation 24-43 weeks were eligible for the study provided that informed consent was given by the parents. Infants with the following conditions were excluded: moribund condition at birth; major congenital malformations; chromosomal abnormalities; gestational age impossible to determine. Infants born to mothers with medical conditions or complications of pregnancy were not excluded because the aim of the study was to construct community at large centile charts rather than those of a "healthy" population.

\section{Assessment of gestational age}

Gestational age was calculated in completed weeks from the findings of an early dating ultrasound performed before 20 weeks gestation. When this was not available, it was calculated from the last menstrual date if the mother had 


\begin{tabular}{|c|c|c|c|c|c|c|c|}
\hline \multirow{2}{*}{$\begin{array}{l}\text { Gestation } \\
\text { (weeks) }\end{array}$} & \multirow[b]{2}{*}{$\mathrm{n}$} & \multicolumn{2}{|c|}{ Birth weight (g) } & \multicolumn{2}{|c|}{$\begin{array}{l}\text { Crown-heel length } \\
(\mathrm{cm})\end{array}$} & \multicolumn{2}{|c|}{ Head circumference $(\mathrm{cm})$} \\
\hline & & Mean & SD & Mean & SD & Mean & SD \\
\hline 24 & 12 & 734 & 44 & 333 & 9 & 234 & 17 \\
\hline 25 & 16 & 786 & 146 & 354 & 11 & 241 & 16 \\
\hline 26 & 11 & 803 & 101 & 355 & 13 & 238 & 8 \\
\hline 27 & 18 & 935 & 174 & 358 & 17 & 250 & 8 \\
\hline 28 & 19 & 1116 & 170 & 376 & 22 & 257 & 12 \\
\hline 29 & 36 & 1227 & 154 & 382 & 19 & 268 & 13 \\
\hline 30 & 24 & 1460 & 282 & 405 & 11 & 281 & 16 \\
\hline 31 & 25 & 1478 & 266 & 410 & 21 & 284 & 20 \\
\hline 32 & 45 & 1711 & 364 & 425 & 21 & 293 & 14 \\
\hline 33 & 65 & 1975 & 302 & 444 & 19 & 304 & 13 \\
\hline 34 & 110 & 2213 & 362 & 455 & 23 & 311 & 13 \\
\hline 35 & 133 & 2423 & 455 & 466 & 24 & 321 & 14 \\
\hline 36 & 211 & 2735 & 395 & 481 & 19 & 328 & 11 \\
\hline 37 & 351 & 2929 & 389 & 485 & 19 & 332 & 11 \\
\hline 38 & 872 & 3071 & 357 & 491 & 17 & 335 & 11 \\
\hline 39 & 1218 & 3198 & 365 & 498 & 17 & 338 & 11 \\
\hline 40 & 1098 & 3278 & 388 & 502 & 16 & 340 & 11 \\
\hline 41 & 505 & 3342 & 386 & 504 & 15 & 343 & 11 \\
\hline 42 & 92 & 3423 & 415 & 508 & 16 & 345 & 13 \\
\hline
\end{tabular}

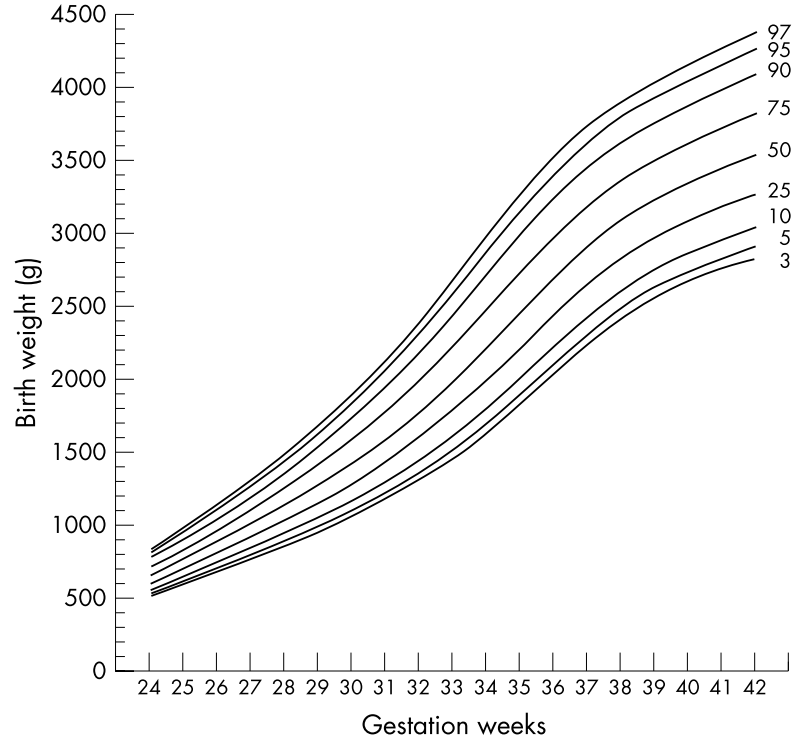

Figure 1 Smoothed centiles for birth weight: boys.

regular menstrual cycles and was certain of her menstrual history. The gestation of each infant was also assessed postnatally using the new Ballard score, ${ }^{15}$ which had been evaluated in our neonatal unit and found to be applicable for Chinese infants. Only infants whose calculated gestation agreed within two weeks with that assessed postnatally were included.

\section{Measurements}

All measurements were collected prospectively. Birth weight was measured by midwives within an hour of birth using an electronic weighing scale (Detecto Scale Co, USA), which was accurate to $5 \mathrm{~g}$ and calibrated before each measurement. Weighing was carried out after the infant had been thoroughly dried and the umbilical cord cut. Within 24-48 hours of birth, the crown-heel length and head circumference of each infant was measured using a neonatometer (Holtain, Dyfed, Wales, UK) and an inelastic tape measure (Harpenden Anthropometric Tape; Holtain) respectively. Crown-heel length was

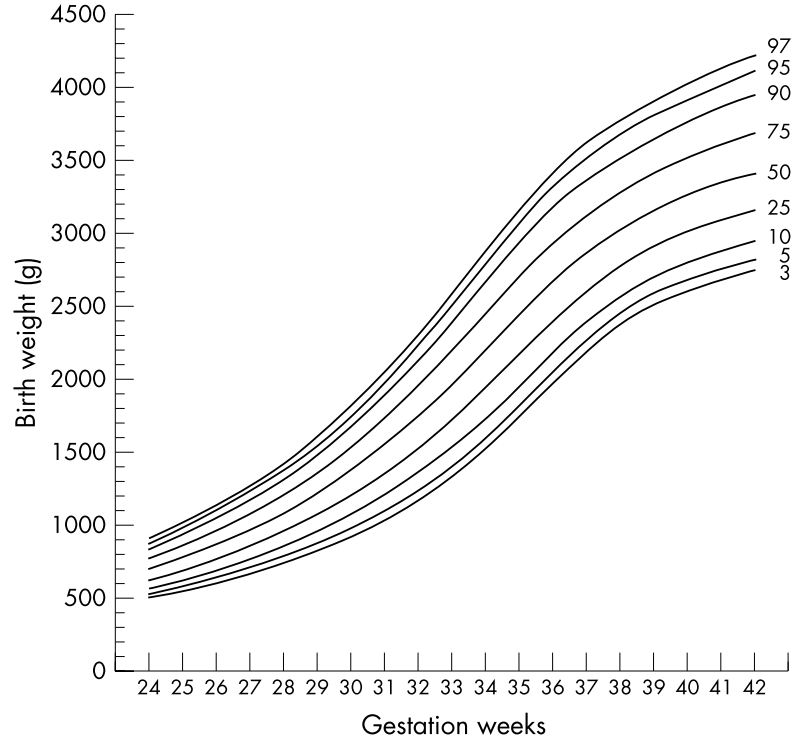

Figure 2 Smoothed centiles for birth weight: girls.

measured from the top of the head to the sole of the foot with the baby lying supine. The head of the infant was held in the Frankfurt horizontal position with the lower edge of the bony orbit and the ear positioned in the same vertical plane. The hips and knees were extended using gentle force. The head circumference was the maximum circumference around the head at the level of the point just above the glabella anteriorly and the top of the occipital bone posteriorly. Three measurements were obtained and the largest one was recorded.

The mean, standard deviation, and 3rd, 5th, 10th, 25th, 50th, 75th, 90th, 95th, and 97th centiles of each variable at each gestation were computed separately for the male and female infants. Centile charts were constructed. The results were compared with those obtained for the 1982-1986 cohort.

\section{Statistical analysis}

The LMS method using maximum penalised likelihood ${ }^{16}$ was used to perform model fitting of the anthropometric centiles for body weight, crown-heel length, and head circumference. 


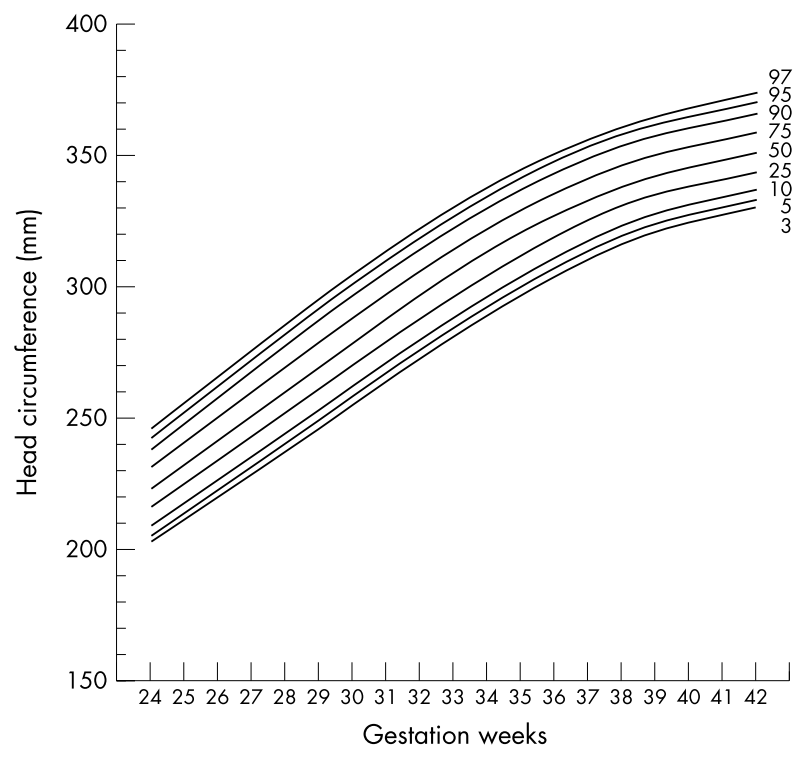

Figure 3 Smoothed centiles for head circumference: boys.

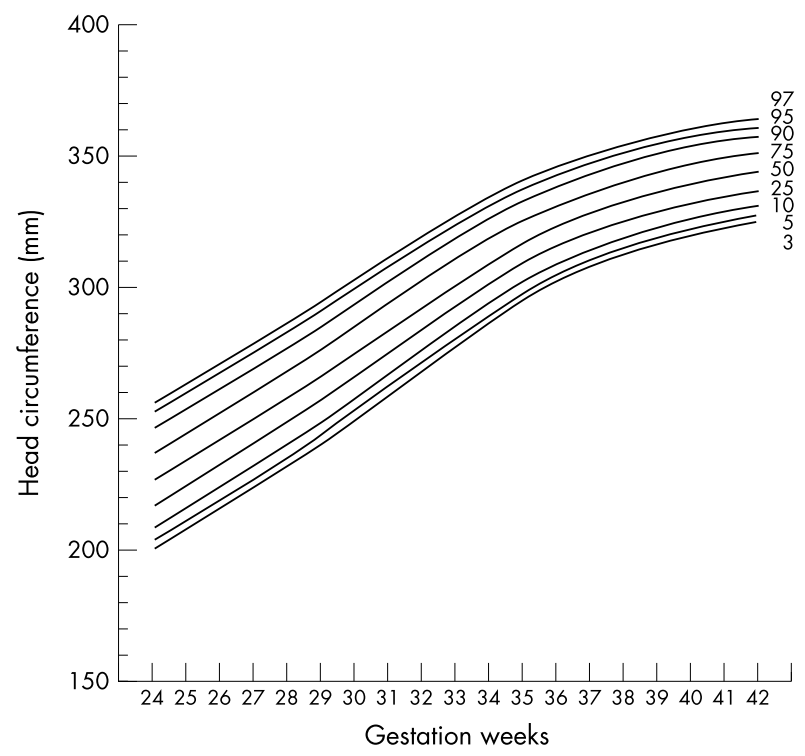

Figure 4 Smoothed centiles for head circumference: girls.

The LMS method estimates the measurement centiles in terms of three age-sex specific cubic spline curves: the L curve (Box-Cox power to transform the data that follow a normal distribution), $M$ curve (median), and S curve (coefficient of variation). In brief, if $\mathrm{Y}(\mathrm{t})$ denotes an independent positive datum-for example, birth weight—at $t$ gestation weeks, the distribution of $\mathrm{Y}(\mathrm{t})$ can be summarised by a normally distributed SD score $(Z)$ as follows:

$\mathrm{Z}=\frac{[\mathrm{Y}(\mathrm{t}) / \mathrm{M}(\mathrm{t})]^{\mathrm{L}(\mathrm{t})}-1}{\mathrm{~L}(\mathrm{t}) \mathrm{S}(\mathrm{t})}$

Once the $\mathrm{L}(\mathrm{t}), \mathrm{M}(\mathrm{t})$, and $\mathrm{S}(\mathrm{t})$ have been estimated for each gestation $\mathrm{t}$, the $100 \alpha$ th centile at $\mathrm{t}$ gestation weeks could be derived from

$\mathrm{C}_{100 \alpha}(\mathrm{t})=\mathrm{M}(\mathrm{t})\left[1+\mathrm{L}(\mathrm{t}) \mathrm{S}(\mathrm{t}) \mathrm{Z}_{\alpha}\right]^{1 / \mathrm{L}(\mathrm{t})}$

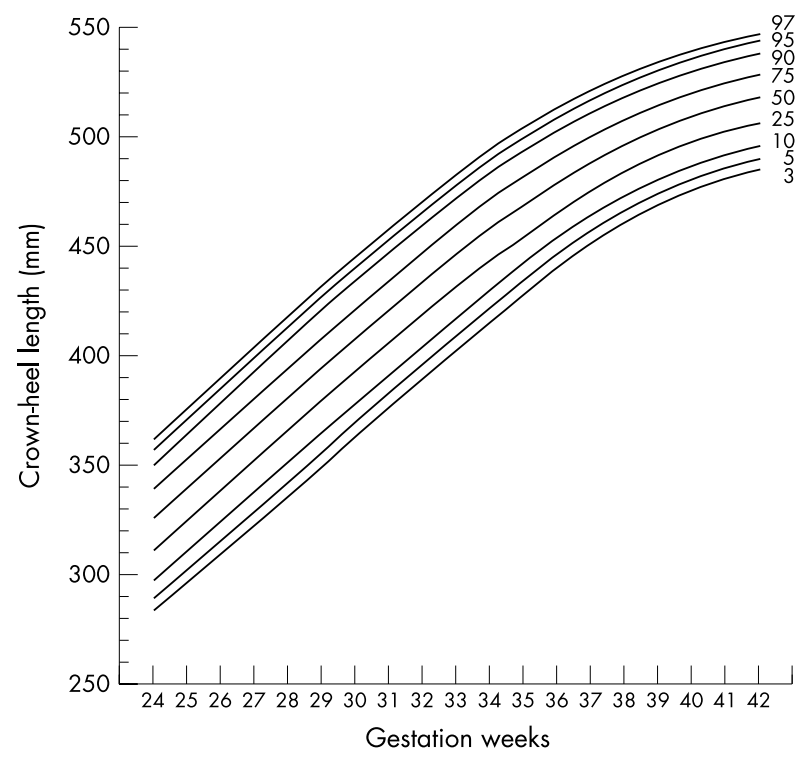

Figure 5 Smoothed centiles for crown-heel length: boys.

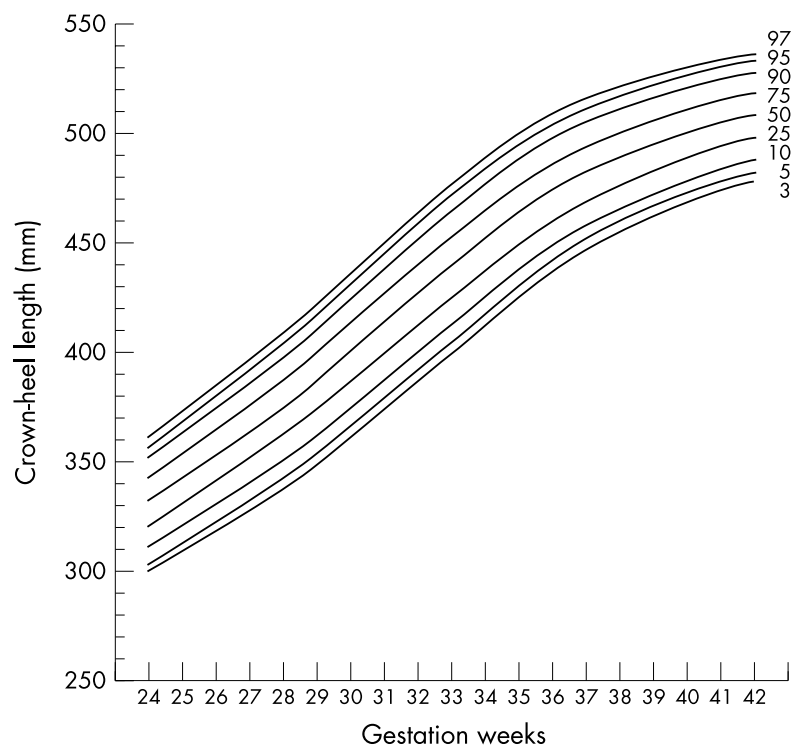

Figure 6 Smoothed centiles for crown-heel length: girls.

where $Z_{\alpha}$ is the $\alpha$ centile of the normal distribution (for example for the 97th centile, $\alpha=0.75$ and $Z_{\alpha}=1.88$ ).

\section{RESULTS}

From October 1998 to September 2000, a total of 104258 infants were born in Hong Kong: 76230 were delivered in the public hospitals and 28028 were delivered in the private hospitals. Measurements were obtained from a total of 10032 singleton infants, or $9.6 \%$ of the total live born infants delivered during this period. Five infants were excluded because of discrepancy between the calculated gestation and that estimated postnatally. The remaining 10027 infants included 9381 infants born in the public hospitals, and 646 infants born in the private hospitals. These represented $12.3 \%$ and $2.3 \%$ of the infants delivered in the public and private hospitals in Hong Kong respectively. After the addition of 307 infants with gestational age $\leqslant 35$ weeks recruited in the subsequent nine months, and excluding infants with gestational age $<24$ weeks and $>42$ weeks, who were too few in number, a total of 10339 infants ( 5478 boys, 4861 girls) were included for analysis. Gestation was estimated by early $(<20$ gestational 
Table 4 Comparisons of birth weight, crown-heel length and head circumference between the 1982-86 and present cohorts: combined data for boys and girls

\begin{tabular}{|c|c|c|c|c|c|c|c|c|c|c|c|}
\hline \multirow{2}{*}{$\begin{array}{l}\text { Gestation } \\
\text { (weeks) }\end{array}$} & \multicolumn{2}{|l|}{$n$} & \multicolumn{3}{|c|}{ Birth weight (g) } & \multicolumn{3}{|c|}{ Crown-heel length $(\mathrm{cm})$} & \multicolumn{3}{|c|}{ Head circumference $(\mathrm{cm})$} \\
\hline & $1982-86$ & Present & $1982-86$ & Present & $p$ Value & $1982-86$ & Present & $\mathrm{p}$ Value & $1982-86$ & Present & $\mathrm{p}$ Value \\
\hline 27 & 20 & 37 & 965 (148) & 1024 (197) & 0.247 & $36.6(1.7)$ & $36.4(1.7)$ & 0.673 & $25.6(0.9)$ & $25.1(1.2)$ & 0.109 \\
\hline 28 & 30 & 46 & 1095 (157) & 1140 (168) & 0.245 & $37.4(1.8)$ & $37.7(2.1)$ & 0.522 & $26.4(1.0)$ & $26.0(1.3)$ & 0.157 \\
\hline 29 & 45 & 62 & $1239(210)$ & $1259(178)$ & 0.596 & $38.5(1.3)$ & $39.1(2.4)$ & 0.131 & $26.9(1.2)$ & $26.9(1.4)$ & 1.000 \\
\hline 30 & 41 & 75 & 1405 (197) & $1471(221)$ & 0.113 & $39.7(2.1)$ & $40.7(1.6)$ & 0.005 & $27.8(1.2)$ & $28.1(1.5)$ & 0.273 \\
\hline 31 & 52 & 66 & $1598(208)$ & $1578(273)$ & 0.663 & $41.1(2.1)$ & $41.9(2.3)$ & 0.054 & $28.5(1.2)$ & $28.7(1.8)$ & 0.492 \\
\hline 32 & 88 & 81 & 1798 (196) & 1793 (389) & 0.915 & 42.6 (2.0) & $42.9(2.4)$ & 0.377 & 29.3 (1.7) & $29.6(1.7)$ & 0.253 \\
\hline 33 & 97 & 154 & 1975 (217) & 2022 (347) & 0.233 & $43.8(2.1)$ & $44.6(2.4)$ & 0.007 & $30.0(1.6)$ & $30.6(1.5)$ & 0.003 \\
\hline 34 & 125 & 211 & 2128 (247) & 2223 (357) & 0.009 & $45.5(2.4)$ & $45.5(2.2)$ & 1.000 & 30.7 (1.5) & $31.1(1.3)$ & 0.011 \\
\hline 35 & 154 & 281 & 2368 (294) & 2470 (436) & 0.010 & 46.7 (2.3) & $46.9(2.3)$ & 0.386 & $31.5(1.4)$ & $32.1(1.4)$ & $<0.001$ \\
\hline 36 & 174 & 486 & 2620 (350) & 2773 (410) & $<0.001$ & 47.1 (1.9) & 48.1 (2.0) & $<0.001$ & 32.5 (1.3) & $33.0(1.3)$ & $<0.001$ \\
\hline 37 & 416 & 783 & 2830 (376) & 2997 (407) & $<0.001$ & $47.9(2.5)$ & 48.9 (1.9) & $<0.001$ & $33.2(1.5)$ & $33.4(1.1)$ & 0.010 \\
\hline 38 & 938 & 1926 & 3025 (342) & 3144 (388) & $<0.001$ & 48.7 (1.7) & $49.6(1.7)$ & $<0.001$ & $33.4(1.3)$ & $33.8(1.2)$ & $<0.001$ \\
\hline 39 & 1926 & 2522 & 3112 (315) & 3246 (377) & $<0.001$ & 49.0 (1.7) & $50.1(1.7)$ & $<0.001$ & 33.8 (1.5) & $34.1(1.1)$ & $<0.001$ \\
\hline 40 & 2145 & 2277 & 3192 (322) & 3349 (400) & $<0.001$ & 49.4 (1.8) & $50.6(1.7)$ & $<0.001$ & 34.1 (1.5) & $34.4(1.2)$ & $<0.001$ \\
\hline 41 & 1442 & 1049 & 3227 (331) & 3433 (418) & $<0.001$ & 49.8 (1.7) & $50.9(1.7)$ & $<0.001$ & $34.3(1.1)$ & $34.7(1.2)$ & $<0.001$ \\
\hline 42 & 752 & 207 & 3265 (341) & 3477 (417) & $<0.001$ & 49.8 (1.9) & $51.3(1.8)$ & $<0.001$ & 34.5 (1.1) & $34.8(1.2)$ & $<0.001$ \\
\hline
\end{tabular}

Values are mean (SD)

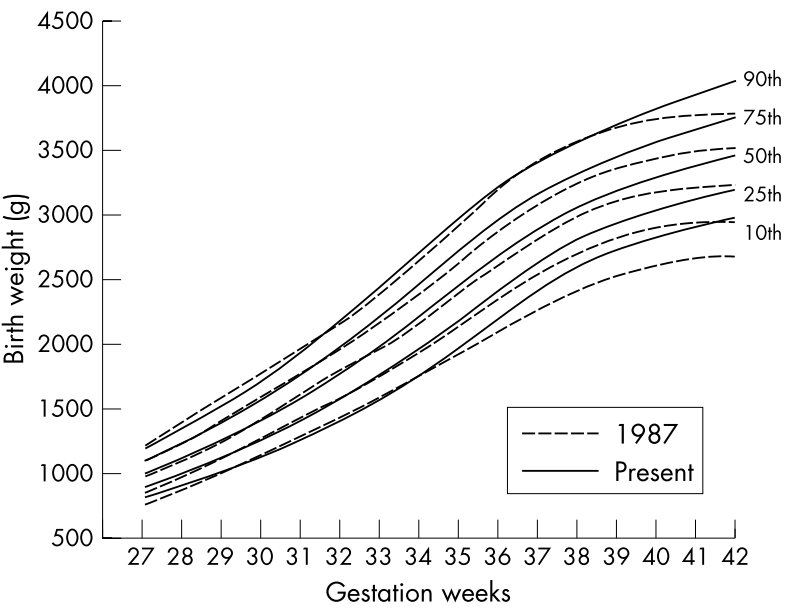

Figure 7 Comparison of smoothed centiles for birth weight between the 1982-1986 and present cohorts: combined data for boys and girls.

weeks) antenatal ultrasonography in 4497 (43.4\%), and maternal last menstrual date (with confirmation by postnatal Ballard score) in 5852 (56.6\%). Most (83\%) of the infants were either first $(44.2 \%)$ or second $(38.8 \%)$ born infants. Para 3 infants constituted $11.9 \%$, and only a small number $(3.8 \%)$ were para 4 or above. This distribution of parity was similar to the general newborn population in the region. Table 1 summarises the characteristics of the parents.

The interobserver agreement of the measurements between the two teams of investigators was assessed on the first 100 infants enrolled in the study, using the Bland-Altman procedure. ${ }^{17}$ The results indicate that the agreement was acceptable, with only small discrepancies in the measurements of both crown-heel length (bias, $-0.19 \mathrm{~mm}$; limit of agreement, -7.72 to $7.73 \mathrm{~mm}$ ) and head circumference (bias, $1.37 \mathrm{~mm}$; limit of agreement, -4.40 to $7.13 \mathrm{~mm}$ ). The birth weight of each infant was measured twice by the midwives using the same electronic weighing scale. The two measurements showed perfect agreement (bias $=0$ ).

Tables 2 and 3 show the distribution of gestational age and summary statistics (mean (SD)) for birth weight, crown-heel length, and head circumference of the boys and girls respectively. At each gestation, each of these measurements was normally distributed. At gestations of 36 weeks or more,

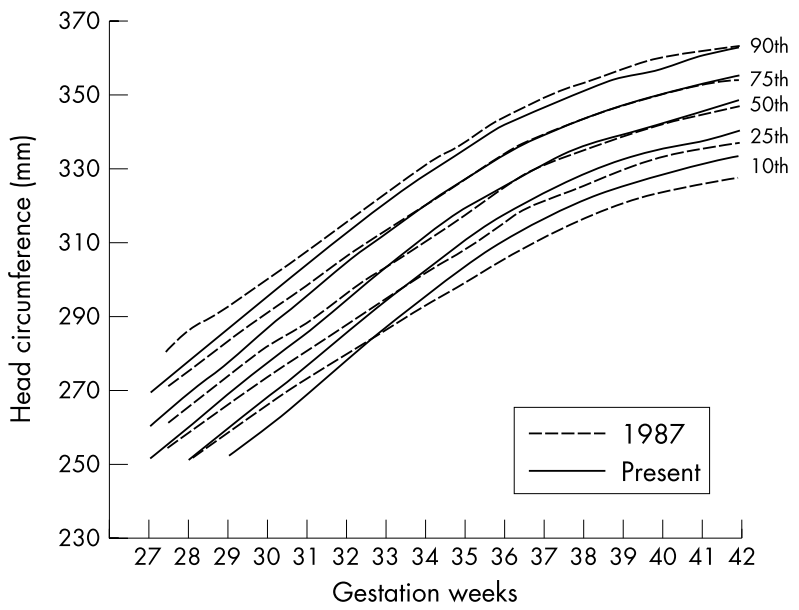

Figure 8 Comparison of smoothed centiles for head circumference between the 1982-1986 and present cohorts: combined data for boys and girls.

the boys consistently exceeded the girls in all three variables. Figures 1-6 show the gestation specific smoothed centile curve for each of the variables for each sex.

The combined data for boys and girls were compared with those for the 1982-1986 cohort, which were not broken down by sex (table 4, figs 7-9). ${ }^{13}$ The present cohort of infants had a significantly higher mean birth weight at each gestation since 34 weeks. The mean differences ranged from $95 \mathrm{~g} \mathrm{(4.5 \% )} \mathrm{at} 34$ weeks to $212 \mathrm{~g}(6.5 \%)$ at 42 weeks. This was accompanied by an upward shift in both the 10th and 90th centiles. No significant differences were observed between the two cohorts for the more preterm infants $<34$ weeks gestation. The differences between the two cohorts were less obvious for crown-heel length and head circumference. Crown-heel length showed an upward shift of almost the entire 10th centile line from 28 to 42 weeks gestation, but the other centile lines showed such a shift only after 38 weeks gestation. Although the mean crown-heel lengths of the present cohort were significantly greater than those of the 1982-1986 cohort after 34 weeks gestation, the differences were small, ranging from 0.2 to $1.5 \mathrm{~cm}(0.4-3 \%)$. The head circumferences showed an upward shift of the 10th centile line after 33 weeks gestation, but the other centile lines were almost identical with those of the 1982-1986 cohort. Similarly to the crown-heel 


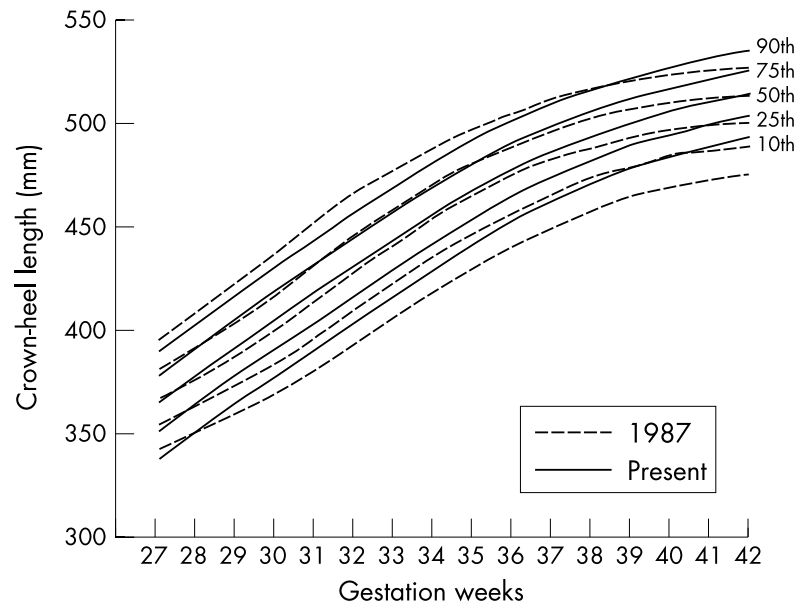

Figure 9 Comparison of smoothed centiles for crown-heel length between the 1982-1986 and present cohorts: combined data for boys and girls.

lengths, mean head circumferences in the present cohort were larger by a small, but significant, margin after 33 weeks gestation, with the differences ranging from 0.2 to $0.6 \mathrm{~cm}$ $(0.6-1.9 \%)$.

\section{DISCUSSION}

Accurate description of gestational age specific physical variables has three prerequisites: (a) reliable and accurate measurement, with not too many observers taking the measurements; $(b)$ accurate recording of gestational age; (c) a sufficiently large sample of babies at various gestations to enable proper statistical description of the data. Most previous studies on gestation specific body size have used data documented in birth records. Using retrospective data has the advantage of enabling the inclusion of a large number of infants, ${ }^{18-20}$ but often requires statistical exclusion of extreme outliers resulting from errors in documentation, erroneous estimation of gestation, or inaccurate measurements. These errors have led to appreciable bimodal distribution of birth weight at each gestation and the apparent excess of large preterm infants often observed in earlier studies. ${ }^{11} 2122$ Estimation of body length and head circumference is particularly prone to error because standard methods and precision instruments are not always used in the routine measurement of these variables in most maternity units. The prospective nature of our study allowed accurate determination of gestational age and measurement of the physical variables. As a result, there were no missing data, and exclusion of extreme outliers in data analysis was not required.

In general, for the construction of centile curves, the larger the sample size the greater the precision in the resulting centiles. We have calculated the minimum sample size at each gestation using the method described by Healy. ${ }^{23}$ As in most similar studies, the number of infants at or near full term was well in excess of the minimum sample size, but the number of the very preterm infants, especially those below 28 weeks gestation, was small. On the basis of the weight distribution of the infants, our total sample size of 5478 would precisely yield the $95 \%$ confidence interval for the 97 th centile within $\pm 5 \%$, and $\pm 6 \%$ to $\pm 14.2 \%$ of its mean at each of 34 th -42 nd and 24th-33rd gestational week respectively for the male infants. For the female infants (total sample size 4861), the corresponding figures are $\pm 6 \%$, and $\pm 10 \%$ to $\pm 18 \%$ respectively. ${ }^{24} 25$

Compared with the local data that we obtained in 1982$1986,{ }^{13}$ the present cohort had a significantly greater mean birth weight at each gestation since 34 weeks. This was accompanied by an upward shift of both the 10th and 90th centiles and much less terminal flattening of the curves after term. The new chart thus redefines the cut off values for the diagnosis of both large and small for gestation. Therefore continuing to use the 1982-1986 standards will result in too few term or near term infants being classified as small for gestation, and too many classified as large for gestation. A similar secular trend in birth weights of term infants has been observed in other populations. ${ }^{20}$ This trend was less obvious with crown-heel length and head circumference, which showed an upward shift only in the 10th centile line. Although significant, the differences in these two variables between the two cohorts are small and of doubtful clinical significance.

There are a number of controversies about the construction of gestation specific growth standards. The first is whether the data should be generated from a non-selected sample of the population or a selected sample of "healthy" subjects with no known factors affecting their growth. As one important application of these standards is to enable clinicians to identify subjects with growth problems, it has been pointed out by Cole ${ }^{26}$ that it is illogical to construct a reference that is targeted at infants who are excluded by definition from the reference sample. It is also doubtful that a reference that truly represents "healthy" growth could ever be made available because many of the factors that affect fetal growth remain unidentified. Thus we did not exclude infants with antenatal factors affecting fetal growth, and the growth reference so constructed provides a neutral baseline for comparing groups without any assumption about the quality of the infants' antenatal growth. The relative excess of infants delivered in public hospitals should not be a problem because infants born in public and private hospitals did not differ significantly in any of the three variables measured, making statistical weighting unnecessary. This is not surprising as the social infrastructure in Hong Kong allows easy and free access to health care for the entire population, and there is no distinct socioeconomic demarcation between the patients of public and private hospitals. In a previous study of Chinese newborns born in Mainland China, Taiwan, and the United States, Yip et $a l^{27}$ showed that economic background had no significant influence on birth weight provided that the pregnant women could meet the basic health and nutrition requirements for adequate fetal growth.

Another controversy is whether preterm infants delivered by caesarean section should be excluded from data analysis. It has been argued that, as infants are delivered before term by interventional means often because of unsatisfactory intrauterine growth or maternal or fetal complications that may compromise fetal growth, birth weight standards that include data obtained from these infants may be skewed towards the lighter end. ${ }^{28}$ We compared the birth weights of our study infants delivered vaginally or by caesarean section before 37 weeks gestation, and did not observe in either sex any significant differences between the two groups at each gestational week. Exclusion of infants born by caesarian section was therefore unnecessary, and their data were included in the construction of the growth standards.

A third controversy is whether there should be one international standard for fetal growth rather than "local standards" representing the growth patterns of different populations. ${ }^{29}{ }^{30}$ Dunn $^{30}$ showed that the small size of infants born in developing countries is to a large extent the result of environmental factors such as maternal malnutrition, and suggested that their birth weights should be compared with an international perinatal growth reference which more truly reflects their growth potential than local charts. We compared the birth weights of our infants with those obtained from the non-indigenous population in Australia, ${ }^{19}$ Norwegian infants, ${ }^{20}$ and British infants in the Oxford area ${ }^{31}$ (table 5). At gestation $>34$ weeks, the 10th, 50th, and 90th centiles of both the Australian and Norwegian infants of either sex were substantially higher than those of our infants. At term $(\geqslant 37$ weeks), the 50th centiles of our infants were less than those of the Norwegian infants by 280-306 g and the Australian infants 
Table 5 Differences of the 10th, 50th, and 90th centiles of gestation specific birth weights $(\mathrm{g})$ of Chinese newborns from those of Australian, ${ }^{19}$ Norwegian, ${ }^{20}$ and British newborns ${ }^{31}$

\begin{tabular}{|c|c|c|c|c|c|c|c|c|c|}
\hline \multirow{2}{*}{$\begin{array}{l}\text { Gestation } \\
\text { (weeks) }\end{array}$} & \multicolumn{3}{|l|}{ Australian } & \multicolumn{3}{|l|}{ Norwegian } & \multicolumn{3}{|l|}{ British } \\
\hline & 10th centile & 50th centile & 90th centile & 10th centile & 50th centile & 90th centile & 10th centile & 50th centile & 90th centile \\
\hline \multicolumn{10}{|l|}{ Male } \\
\hline 24 & -32 & 28 & 95 & 13 & 73 & 120 & 48 & 88 & 205 \\
\hline 25 & -28 & 15 & 71 & 7 & 65 & 106 & -18 & 20 & 41 \\
\hline 26 & -24 & 30 & 74 & 1 & 60 & 99 & -44 & -20 & -6 \\
\hline 27 & -102 & -14 & 70 & 13 & 71 & 105 & -52 & -34 & -30 \\
\hline 28 & -93 & 29 & 70 & 17 & 89 & 130 & -33 & -21 & -30 \\
\hline 29 & -100 & 61 & 96 & 40 & 121 & 166 & -10 & 21 & 16 \\
\hline 30 & -88 & 58 & 122 & 77 & 158 & 197 & 32 & 58 & 52 \\
\hline 31 & 10 & 67 & 113 & 120 & 207 & 243 & 60 & 97 & 83 \\
\hline 32 & -49 & 95 & 418 & 166 & 255 & 283 & 91 & 125 & 98 \\
\hline 33 & 25 & 114 & 185 & 195 & 284 & 305 & 105 & 134 & 105 \\
\hline 34 & 37 & 117 & 133 & 217 & 307 & 323 & 107 & 147 & 123 \\
\hline 35 & 97 & 116 & 130 & 202 & 312 & 345 & 87 & 136 & 120 \\
\hline 36 & 83 & 107 & 116 & 173 & 307 & 366 & 43 & 117 & 116 \\
\hline 37 & 100 & 151 & 213 & 170 & 306 & 398 & 0 & 101 & 163 \\
\hline 38 & 151 & 204 & 224 & 216 & 324 & 369 & -29 & 94 & 164 \\
\hline 39 & 173 & 217 & 241 & 253 & 352 & 391 & -17 & 107 & 181 \\
\hline 40 & 195 & 245 & 276 & 255 & 370 & 421 & -5 & 115 & 176 \\
\hline 41 & 214 & 277 & 310 & 239 & 357 & 415 & 4 & 97 & 130 \\
\hline 42 & 161 & 235 & 289 & 186 & 305 & 364 & -69 & 5 & 19 \\
\hline \multicolumn{10}{|l|}{ Female } \\
\hline 24 & -13 & -27 & -46 & -33 & -17 & -1 & 47 & 53 & 144 \\
\hline 25 & 5 & -18 & -25 & -35 & -3 & 20 & 15 & 22 & 25 \\
\hline 26 & 0 & 12 & 10 & -30 & 12 & 45 & 20 & 17 & 20 \\
\hline 27 & -23 & -2 & 29 & -18 & 33 & 79 & 37 & 28 & 29 \\
\hline 28 & -80 & 2 & 45 & 10 & 72 & 130 & 70 & 52 & 45 \\
\hline 29 & -49 & 47 & 48 & 56 & 122 & 193 & 101 & 97 & 98 \\
\hline 30 & -9 & 62 & 75 & 106 & 172 & 250 & 146 & 132 & 135 \\
\hline 31 & -43 & 58 & 130 & 152 & 218 & 295 & 177 & 168 & 170 \\
\hline 32 & 5 & 52 & 121 & 190 & 252 & 326 & 205 & 192 & 191 \\
\hline 33 & 8 & 97 & 146 & 218 & 272 & 336 & 208 & 197 & 201 \\
\hline 34 & 44 & 85 & 168 & 229 & 280 & 323 & 154 & 155 & 158 \\
\hline 35 & 92 & 76 & 188 & 207 & 276 & 323 & 92 & 116 & 128 \\
\hline 36 & 54 & 78 & 148 & 164 & 273 & 343 & 34 & 88 & 108 \\
\hline 37 & 54 & 120 & 175 & 154 & 280 & 365 & -16 & 70 & 115 \\
\hline 38 & 110 & 168 & 232 & 180 & 303 & 382 & -40 & 68 & 132 \\
\hline 39 & 139 & 190 & 233 & 214 & 325 & 393 & -31 & 80 & 153 \\
\hline 40 & 174 & 220 & 264 & 239 & 345 & 404 & -16 & 100 & 164 \\
\hline 41 & 200 & 249 & 302 & 225 & 344 & 402 & 10 & 109 & 142 \\
\hline 42 & 163 & 226 & 299 & 173 & 306 & 374 & -47 & 46 & 69 \\
\hline
\end{tabular}

by $120-230 \mathrm{~g}$. The British data, which were for infants born 18-24 years ago, were more similar to our own, but there remained a significant difference of about $100 \mathrm{~g}$ between the 50th centiles of the two populations from 31 to 41 weeks gestation. A similar difference was also present between the 90th centile lines. We have previously compared the birth weights of our 1982-1986 cohort $^{13}$ with those obtained from a British ${ }^{32}$ and an Australian ${ }^{33}$ population over 30 years ago, and showed that the white infants were heavier throughout the third trimester, especially at gestations $>37$ weeks. In both the 1982-1986 and the present cohorts, no maternal or environmental factors such as maternal malnutrition that could adversely affect fetal growth could be identified. It thus appears that, compared with white infants, there is a genuine genetic predisposition that leads to the smaller size of our infants.

Like all similar studies, the cross sectional anthropometric data obtained in this study do not reflect the intrauterine growth of the fetuses and are unsuitable for use in the evaluation of fetal growth velocity. Longitudinal study of individual fetuses would be required. Our study, however, provides an updated reference for evaluation of the size of Southern Chinese newborns of 24-42 weeks gestation and the identification of infants at risk of developing complications associated with excessively small or large size. Given the important relation between body size at birth and the future health of newborns, ${ }^{34-40}$ these charts should be useful in the care of newborns of ethnic Chinese origin.
Members of the Hong Kong Neonatal Measurements Working Group:

A K H Chan (Caritas Medical Centre), Y C Tsao (Hong Kong Sanatorium), R K N Yuen (Kwong Wah Hospital), C T Tong (Our Lady of Maryknoll Hospital), B W Y Young, H T Ho (Pamela Youde Nethersole Eastern Hospital), T F Fok, P C Ng, A M Y Chang (Prince of Wales Hospital), C B Chow (Princess Margaret Hospital), W H Lee (Queen Elizabeth Hospital), B C C Lam (Queen Mary Hospital and Tsan Yuk Hospital), N S Kwong (Tuen Mun Hospital), A K Y Lee (Union Hospital), H B Chan (United Christian Hospital).

\section{ACKNOWLEDGEMENTS}

The study was supported by a grant from the Health Care and Promotion Fund Committee, the Hospital Authority, Hong Kong.

\section{Authors' affiliations}

T F Fok, H K So, P C Ng, Department of Paediatrics, Chinese University of Hong Kong, Prince of Wales Hospital, Hong Kong

E Wong, J Lau, Centre of Clinical Trials and Epidemiology Research, Chinese University of Hong Kong, Prince of Wales Hospital, Hong Kong A Chang, Department of Obstetrics and Gynaecology, Chinese University of Hong Kong, Prince of Wales Hospital, Hong Kong C B Chow, Department of Paediatrics, Princess Margaret Hospital, Hong Kong

W H Lee, Department of Paediatrics, Queen Elizabeth Hospital, Hong Kong 


\section{REFERENCES}

1 Wilcox AJ, Skjaerven R. Birth weight and perinatal mortality: the effect of gestational age. Am J Public Health 1992;82:378-82.

2 Wilcox AJ, Russell IT. Birthweight and perinatal mortality. II. On weight-specific mortality. Int J Epidemiol 1983;12:319-25.

3 Susser M, Marolla FA, Fleiss J. Birth weight, fetal age and perinatal mortality. Am J Epidemiol 1972;96:197-204.

4 Koops BL, Morgan L, Battaglia FC. Neonatal mortality risk in relation to birth weight and gestational age: update. J Pediatr 1982;101: 969-77.

5 Williams RL, Creasy RK, Cunningham GC, et al. Fetal growth and perinatal viability in California. Obstet Gynecol 1982;59:624-32.

6 Allen MC. Developmental outcome and followup of the small for gestational age infant. Semin Perinatol 1984;8:123-56.

7 Commey JO, Fitzhardinge PM. Handicap in the preterm small-for-gestational age infant. J Pediatr 1979;94:779-86.

8 Melve KK, Gjessing HK, Skjaerven R, et al. Infants' length at birth: an independent effect on perinatal mortality. Acta Obstet Gynecol Scand 2000;79:459-64.

9 Commey JOO, Fitzhardinge PM. Handicap in the preterm small-for-gestational-age infant. J Pediatr 1979;94:779.

10 Hong Kong Government Information Centre. Hong Kong Year Book 1999. Hong Kong: Hong Kong Government Press, 2000.

11 Lubchenco LO, Hansman C, Dressler $M$, et al. Intrauterine growth estimated from liveborn birth-weight data at 24 to 42 weeks of gestation. Pediatrics 1963;32:793-80.

12 Lubchenco LO, Hansman C, Boyd E. Intrauterine growth in length and head circumference as estimated from livebirths at gestation ages from 26 to 42 weeks. Pediatrics 1966:37:403-8.

13 Fok TF, Lam TK, Lee N, et al. A prospective study on the intrauterine growth of Hong Kong Chinese babies. Biol Neonate 1987;51:312-23.

14 Hong Kong Government. 1996 Population By-Census Main Report. Hong Kong: Hong Kong Government Press, 1997.

15 Ballard JL, Khoury JC, Wedig K, et al. New Ballard Score, expanded to include extremely premature infants. J Pediatr 1991;119:417

16 Cole TJ, Freeman JV, Preece MA. British 1990 growth reference centiles for weight, height, body mass index and head circumference fitted by maximum penalized likelihood. Stat Med 1998;17:407-29.

17 Bland JM, Altman DG. Statistical methods for assessing agreement between two methods of clinical measurement. Lancet 1986;1:307-10.

18 Arbuckle TE, Wilkins R, Sherman GJ. Birth weight percentiles by gestational age in Canada. Obstet Gynecol 1993:81:39-48.

19 Roberts CL, Lancaster PA. Australian national birthweight percentiles by gestational age. Med J Aust 1999;170:114-18.

20 Skjaerven R, Gjessing HK, Bakketeig LS. Birthweight by gestational age in Norway. Acta Obstet Gynecol Scand 2000;79:440-9.
21 Milner RD, Richards B. An analysis of birth weight by gestational age of infants born in England and Wales, 1967 to 1971. J Obstet Gynaecol Br Commonw 1974;81:956-67.

22 Gruenwald P. Growth of the human fetus. I. Normal growth and its variation. Am J Obstet Gynecol 1966;94:1112-19.

23 Healy HJ. Statistics of growth standards. In: Falker F, Tanner JM, eds. Human growth. A comprehensive treatise: methodology, ecological, genetic, and nutritional effects on growth. New York: Plenum Press, 1986;3:47-58

24 Altman DG, Chitty LS. Charts of fetal size. 1. Methodology. Br J Obstet Gynaecol 1994;101:29-34.

25 Royston P. Constructing time-specific reference ranges. Stat Med 1991:10:675-90.

26 Cole TJ. Some questions about how growth standards are used. Horm Res 1996;45(suppl 2):18-23.

27 Yip R, Li Z, Chong WH. Race and birth weight: the Chinese example. Pediatrics 1991;87:688-93.

28 Lucas A Cole TJ, Gandy GM. Birthweight centiles in preterm infants reappraised. Early Hum Dev 1986;13:313-22.

29 Wharton BA. Sorrento studies of birthweight. Case for international reference data. Acta Paediatr Scand Suppl 1985;319:170-9.

30 Dunn PM. A perinatal growth chart for international reference. Acta Paediatr Scand Suppl 1985:319:180-7.

31 Yudkin PL, Aboualfa M, Eyre JA, et al. New birthweight and head circumference centiles for gestational ages 24 to 42 weeks. Early Hum Dev 1987; 15:45-52.

32 Thomson AM, Billewicz WZ, Hytten FE. The assessment of fetal growth J Obstet Gynaecol Br Commonw 1968;75:903-16.

33 Betheras FR, White JG, Betheras GW. Intrauterine growth in an Australian population. Aust N Z J Obstet Gynaecol 1969;9:3-61

34 Barker DJ, Martyn CN, Osmond C, et al. Growth in utero and serum cholesterol concentrations in adult life [see comments]. BM 1993;307: 1524-7.

35 Barker DJ, Osmond C, Simmonds SJ, et al. The relation of small head circumference and thinness at birth to death from cardiovascular disease in adult life. BM 1993;306:422-6.

36 Barker DJ. Fetal growth and adult disease. Br J Obstet Gynaecol 1992;99:275-6.

37 Barker DJ, Godfrey KM, Fall C, et al. Relation of birth weight and childhood respiratory infection to adult lung function and death from chronic obstructive airways disease. BM 1991;303:671-5.

38 Barker DJ, Bull AR, Osmond C, et al. Fetal and placental size and risk of hypertension in adult life [see comments]. BM 1990;301:259-62.

39 Barker DJ, Winter PD, Osmond C, et al. Weight in infancy and death from ischaemic heart disease [see comments]. Lancet 1989:2:577-80.

40 Barker DJ, Osmond C, Golding J, et al. Growth in utero, blood pressure in childhood and adult life, and mortality from cardiovascular disease. BM 1989;298:564-7.

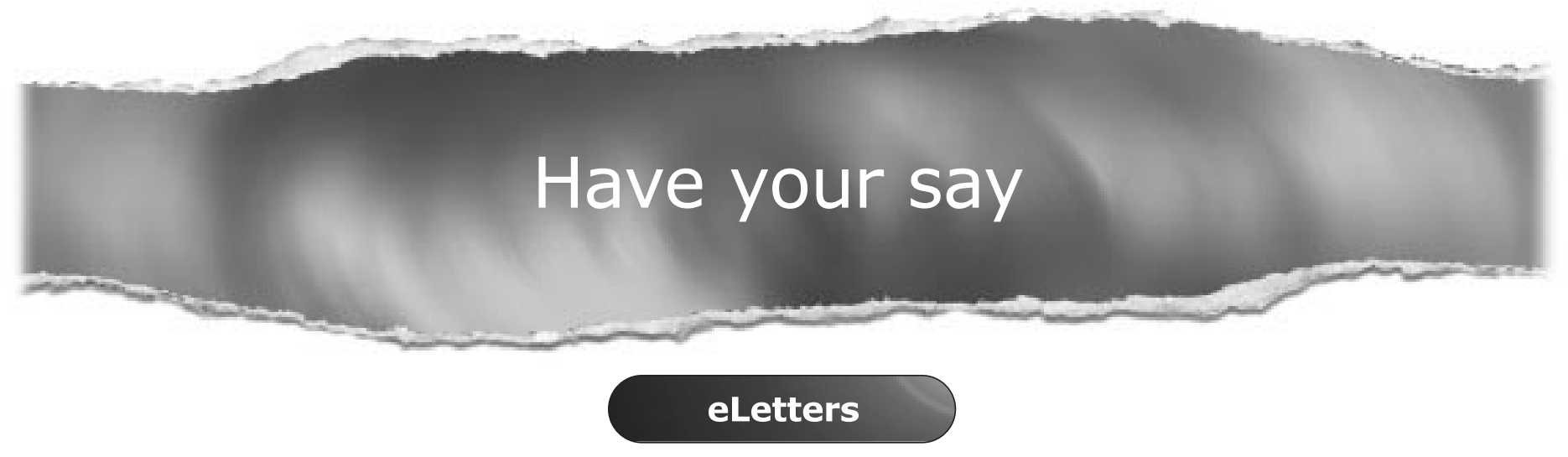

If you wish to comment on any article published in Archives of Disease in Childhood you can send an eLetter using the eLetters link at the beginning of each article. Your response will be posted on Archives of Disease in Childhood online within a few days of receipt (subject to editorial screening).

\section{www.archdischild.com}

